\title{
Laparoscopic Surgeries during Pregnancy - Related Anaesthetic Concerns
}

Tomar $\mathrm{GS}^{1 *}$, Sethi A², Godwin R 3 , Saxena $\mathrm{A}^{4}$

${ }^{1}$ Senior Resident, (D.M. ${ }^{\text {st }}$ Year), Department of Neuroanaesthesiology and Critical care, AIIMS, New Delhi, India.

${ }^{2}$ Associate professor, Department of Anesthesiology and Critical care, N.S.C.B. Medical College, Jabalpur, M.P., India.

${ }^{3}$ Assistant Professor, Department of Anesthesiology and Critical care, N.S.C.B. Medical College, Jabalpur, M.P., India.

${ }^{4}$ Department of Anaesthesiology and Critical care, J.P.N.A. Trauma Center, A. I. I. M. S., New Delhi, India.

\begin{abstract}
Pregnancy is no longer considered a contraindication to laparoscopic surgery. The advantages include less exposure of the fetus to possibly toxic agents, smaller incisions, decreased pain, less need for analgesics, more rapid recovery and mobilization. By understanding the physiological and pharmacological changes during pregnancy, surgery and related anesthesia risk can be minimized on mother and fetus. Appendicitis, cholecystitis, ovarian torsion and trauma are among the more common indications for surgical intervention. Less commonly, cardiac and neurological procedures are undertaken during pregnancy.
\end{abstract}

Keywords: Pregnancy; Laparoscopy; Anaesthesia; Complications.

\section{*Corresponding Author:}

Dr. Gaurav Singh Tomar,

Senior Resident, (D.M. 1st Year), Department of Neuroanaesthesiology and Critical Care, AIIMS, New Delhi - 110029, India.

Tel: +91-9716700197

E-mail: spunkygst@gmail.com

Received: May18, 2015

Accepted: July 11, 2015

Published: July 27, 2015

Citation: Tomar GS, Sethi A, Godwin R, Saxena A (2015) Laparoscopic Surgeries during Pregnancy - Related Anaesthetic Concerns. Int J Anesth Res. 3(6), 135-138. doi: http://dx.doi.org/10.19070/2332-27801500033

Copyright: Tomar GS $^{\mathcal{O}}$ 2015. This is an open-access article distributed under the terms of the Creative Commons Attribution License, which permits unrestricted use, distribution and reproduction in any medium, provided the original author and source are credited.

\section{Introduction}

Approximately 1 in 500 to 1 in 635 women will require non-obstetrical abdominal surgery during their pregnancies $[1,2]$. The most common non-obstetrical surgical emergencies complicating pregnancy are acute appendicitis, cholecystitis, and intestinal obstruction [1]. Other conditions that may require operations during pregnancy include ovarian cysts, masses or torsion, symptomatic cholelithiasis, adrenal tumors, splenic disorders, symptomatic hernias, complications of inflammatory bowel diseases, and abdominal pain of unknown etiology. During its infancy, some argued that laparoscopy was contraindicated during pregnancy due to concerns for uterine injury and fetal perfusion. As surgeons have gained more experience with laparoscopy it has become the preferred modality of treatment for many surgical diseases in the gravid patient [3].

\section{Indications}

"Laparoscopic treatment of acute abdominal disease has the same indications in pregnant and non-pregnant patients"

Once the decision to operate has been made, the surgical approach (laparotomy versus laparoscopy) should be determined based on the skills of the surgeon and the availability of the appropriate staff and equipment. An appropriate discussion with the patient regarding the risks and benefits of surgical intervention should be undertaken. Benefits of laparoscopy during pregnancy appear similar to those benefits in non-pregnant patients including less postoperative pain, less postoperative ileus, decreased length of hospital stays and faster return to work [4, 6, 8-10].

\section{Laparoscopy and Pregnancy related risk}

"Laparoscopy can be safely performed regardless of any trimester of pregnancy"

Operative intervention may be performed in any trimester of pregnancy. Historical recommendations were to delay surgery until the second trimester in order to reduce the rates of spontaneous abortion and preterm labor [11]. Recent literature has shown that pregnant patients may undergo laparoscopic surgery safely during any trimester without any increased risk to the mother or fetus $[4,10,12,15]$. Postponing necessary operations until after parturition may, in some cases, increase the rates of complications for both mother and fetus $[12,16]$.

It has been suggested that the gestational age limit for successful completion of laparoscopic surgery during pregnancy is 26 to 28 weeks [5]. This has been refuted by several studies in which laparoscopic cholecystectomy and appendectomy have been success- 
fully performed late in the third trimester $[13,15,17,18]$. Although laparoscopy can be performed safely in pregnancy with good fetal and maternal outcomes, the long-term effects to the children have not been well studied. One recent study evaluated eleven children from one to eight years and found no growth or developmental delay [7].

There are many advantages of laparoscopy in the pregnant patient including: decreased fetal respiratory depression due to diminished postoperative narcotic requirements $[6,19,20]$, lower risk of wound complications [19, 21, 22], diminished postoperative maternal hypoventilation [19, 20], and decreased risk of thromboembolic events. The improved visualization in laparoscopy may reduce the risk of uterine irritability by decreasing the need for uterine manipulation [23]. Decreased uterine irritability results in lower rates of spontaneous abortion and preterm delivery [24].

\section{Pre-anaesthetic assessment and optimization}

Many signs and symptoms often associated with cardiac disease, such as dyspnoea, heart murmurs and peripheral oedema are common during normal pregnancy. ECG changes during pregnancy include left axis deviation, premature beats and non-specific ST and T-wave changes. During radiological investigations, fetal exposure should be minimized. Results of relevant blood tests should be available and cross - matched blood must be ordered for all major surgery. Pre-medication should always include aspiration prophylaxis such as ranitidine, sodium citrate and metoclopramide. Aspiration prophylaxis is recommended from the beginning of the second trimester.

\section{Intraoperative considerations}

The anaesthesiologist has the following goals inside operating room [25]

1. Optimize and maintain normal maternal physiological function;

2. Optimize and maintain utero-placental blood flow and oxygen delivery;

3. Avoid unwanted drug effects on the fetus;

4. Avoid stimulating the myometrium (oxytocic effects);

5. Avoid awareness during general-anaesthesia.

Resuscitation, if required, should be vigorously performed following the usual advanced life support (ACLS) or advanced trauma life support (ATLS) protocols, with the addition of left lateral tilt to avoid supine hypotension.

Airway management by a face mask, a laryngeal mask or tracheal intubation can be technically difficult because of increased anteroposterior chest wall diameter, breast enlargement, laryngeal oedema and weight gain affecting the soft tissues of the neck. Nasal tube airways should be avoided in pregnancy because of increased vascularity of mucous membranes.

Analgesia should be prescribed where appropriate to avoid the detrimental effects of stress to the mother and fetus. Non-steroidal anti-inflammatory drugs should be avoided, because of the risk of premature closure of the ductus arteriosus. However, low dose aspirin, even when taken regularly, appears safe in this respect.
Pregnancy is associated with lower anaesthetic requirements, although the mechanism for this is unknown. The minimum alveolar concentration (MAC) for inhalation anaesthetics is reduced by $30 \%$ as early as $8-12$ weeks gestation. IV drugs that induce general anaesthesia should also be given in lower doses. Choice among IV induction agents in pregnancy is a controversy, since we are looking for a safest available drug in pregnant patient undergoing surgery choice would be based on benefits mother and fetus outweighs risk or side effects related with its use. In author's opinion, thiopentone sodium being a hydrophilic drug has minimal permeability to placental barrier matches most of it. Nitrous oxide is avoided as animal studies provide evidence that it is a potent inhibitor of methionine synthase. In addition to it may further exacerbate the hypoxemia caused because of $\mathrm{CO}_{2}$ insufflation intraperitoneally. Marked reduction of plasma cholinesterase concentration (30\% reduction) theoretically causes succinylcholine, ester local anaesthetics and certain other drugs to have prolonged effects. However, this is counterbalanced by increased volumes for drug distribution. Therefore, it is of consequence, if at all, in the postpartum period, when enzyme activity remains depressed but the volume of distribution begins to normalize. Among non depolarizing muscle relaxants, vecuronium and cisatracurium are better options of choice devoid of vagolytic and histamine releasing properties. Neuromuscular drug monitoring is recommended.

\section{Patient Positioning}

Aortocaval compression is a major hazard from 20 weeks onwards (and sometimes even earlier); when the pregnant patient is placed in a supine position, the gravid uterus places pressure on the inferior vena cava resulting in decreased venous return to the heart. This decrease in venous return results in significant reduction in cardiac output with concomitant maternal hypotension, and decreased placental perfusion during surgery [26, 27]. This effect may be exacerbated by regional or general anaesthesia when normal compensatory mechanisms are attenuated or abolished. Aortocaval compression is only effectively avoided by the use of the lateral position. It can be decreased by uterine displacement through wedging or manual displacement. Placing the patient in a left lateral decubitus position will shift the uterus off the vena cava improving venous return and cardiac output.

\section{Insufflation Pressure}

The potential for adverse consequences from $\mathrm{CO}_{2}$ insufflation in the pregnant patient has led to apprehension over its use. As such, some authors advocate gasless laparoscopy in pregnant patients, but this technique not been widely adopted [28-30].

The pregnant patient's diaphragm is upwardly displaced by the growing fetus, which results in decreased residual lung volume and functional residual capacity [31]. Upward displacement of the diaphragm by pneumoperitoneum is more worrisome in a pregnant patient with existing restrictive pulmonary physiology. Some have recommended intra abdominal insufflation pressures be maintained at less than $12 \mathrm{mmHg}$ to avoid worsening pulmonary physiology in gravid women [32]. Others have argued that insufflation less than $12 \mathrm{mmHg}$ may not provide adequate visualization of the intra-abdominal cavity. Pressures of $15 \mathrm{mmHg}$ have been used during laparoscopy in pregnant patients without increasing adverse outcomes to the patient or her fetus $[13,15]$.

Because $\mathrm{CO}_{2}$ exchange occurs with intraperitoneal insufflation 
there has been concern for deleterious effects to the fetus from pneumoperitoneum. Some animal studies have confirmed fetal acidosis with associated tachycardia, hypertension and hypercapnoea during $\mathrm{CO}_{2}$ pneumoperitoneum $[33,34]$, while other animal studies contradict these findings [35]. There are no data showing detrimental effects to human fetuses from $\mathrm{CO}_{2}$ pneumoperitoneum [5].

\section{Intra-operative $\mathrm{CO}_{2}$ Monitoring (capnography)}

Fetal acidosis and associated fetal instability in $\mathrm{CO}_{2}$ pneumoperitoneum have been documented in animal studies, though no longterm effects from these changes have been identified [33, 36]. Fetal acidosis with insufflation has not been documented in the human fetus, but concerns over potential detrimental effects of acidosis have led to the recommendation of maternal $\mathrm{CO}_{2}$ monitoring [38, 39]. Initially, there was debate over maternal blood gas monitoring of arterial carbon dioxide $\left(\mathrm{PaCO}_{2}\right)$ versus end-tidal carbon dioxide $\left(\mathrm{ETCO}_{2}\right)$ monitoring, but the less invasive capnography has been demonstrated to adequately reflect maternal acid-base status in humans [39]. Several large studies have documented the safety and efficacy of $\mathrm{EtCO}_{2}$ measurements in pregnant women $[5,13$, 15] making routine blood gas monitoring unnecessary.

\section{Venous Thromboembolic (VTE) Prophylaxis}

Pregnancy is associated with a hypercoagulable state because of increased pro-coagulant factors. The incidence of thromboembolic complications is at least five times greater during pregnancy with a $0.1-0.2 \%$ incidence of deep venous thrombosis [40]. $\mathrm{CO}_{2}$ pneumoperitoneum may increase the risk of deep venous thrombosis by predisposing to venous stasis. Insufflation of $12 \mathrm{mmHg}$ causes a significant decrease in blood flow that cannot be completely reversed with intermittent pneumatic compression devices or intermittent electric calf stimulators [41].

Although there is little research on prophylaxis for deep venous thrombosis in the pregnant patient, general principles for laparoscopic surgery apply. Because of the increased risk of thrombosis, prophylaxis with pneumatic compression devices both intraoperatively and postoperatively and early postoperative ambulation are recommended. There are no data regarding use of unfractionated or low molecular weight heparin for prophylaxis in pregnant patients undergoing laparoscopy, though its use has been suggested in patients undergoing extended major operations [42]. In patients who require anticoagulation during pregnancy, heparin has proven safe and is the agent of choice [43].

\section{Perioperative Care}

\section{Fetal Heart Monitoring}

While intraoperative fetal heart rate monitoring was once thought to be the most accurate method to detect fetal distress during laparoscopy, no intraoperative fetal heart rate abnormalities have been reported in the literature [12]. This has led some to recommend preoperative and postoperative monitoring of the fetal heart rate with no increased fetal morbidity having been reported. $[13,15]$.

\section{Obstetrical Consultation}

Maternal and fetal monitoring should be part of any pregnant patient's care and continue throughout her hospitalization, but the timing of a formal obstetric consultation will vary based on availability of the consultant and the severity of the patient's condition. Delaying the treatment of an acute abdominal process to obtain such a consultation should be avoided as treatment delay may increase the risk of morbidity and mortality to the mother and fetus [44].

\section{Tocolytics}

Tocolytics should not be used prophylactically in pregnant women undergoing surgery but should be considered perioperatively when signs of Threatened preterm labor are present. The specific agent and indications for the use of tocolytics should be individualized and based on the recommendation of an obstetrician [45]. No literature supports the use of prophylactic tocolytics.

\section{Anesthetic drugs in pregnancy}

In general, pregnancy does not affect the choice of medications, or their doses; however, pregnant women are more sensitive to the effects of some anesthetic agents, so neuromuscular blockade and effects of volatile anesthetics should be monitored.

\section{Anesthetic dosing}

Induction agents: Induction dose of propofol is unchanged in pregnancy [46]. The induction dose of thiopental is decreased in pregnancy by 18 to 35 percent [47].

Neuromuscular blockers: Pregnant patients are more sensitive to the action of vecuronium and rocuronium [48], but have increased clearance of both of these medications [49]. Succinylcholine dose is unchanged in pregnancy; its volume of distribution is increased, but systemic pseudocholinesterase activity is decreased [50, 51], resulting in variability in duration of action. Pregnant women develop less prominent fasciculation, but more prominent bradycardia in response to succinylcholine.

Volatile anesthetics: The MAC for volatile anesthetic agents is decreased by about to 30 percent, beginning in the first trimester $[52,53]$.

Uterine-effects: Potent inhalational agents, such as isoflurane, desflurane, and sevoflurane decrease uterine tone; thus, they act to inhibit labor during the operative procedure [54]. Inhaled nitrous oxide (either alone or as a 50 percent mixture with oxygen) has no effect on uterine tone, maternal hemodynamic status, or fetal heart rate variability [55].

\section{Summary}

Laparoscopy results in multiple postoperative benefits allowing for quicker recovery and shorter hospital stay. These advantages explain the increasing success of laparoscopy, which is recommended for many surgical procedures. Improved knowledge of the intraoperative repercussions of laparoscopy permits safe management of patients with more and more severe cardiorespiratory disease, who may subsequently benefit from the multiple postoperative advantages offered by this technique. The most remarkable concerns regarding anaesthesia in laparoscopic procedures are: 
1. Avoid or minimize aortocaval compression.

2. Perform surgery in the second trimester where possible. Avoid elective surgery until after delivery.

3. Maintain normal maternal physiology. Optimize uteroplacental perfusion and avoid fetal asphyxia.

4. Avoid unwanted drug effects on the fetus, but be aware that no anaesthetic agents have been shown to be teratogenic in the clinical use.

\section{References}

[1]. Kammerer WS (1979) Nonobstetric surgery during pregnancy. The Medical Clinics of North America 63(6): 1157-1164.

[2]. Kort B, Katz VL, Watson WJ (1993) The effect of nonobstetric operation during pregnancy. Surg Gynecol Obstet 177(4): 371-376.

[3]. Fallon WF Jr, Newman JS, Fallon GL, Malangoni MA (1995) The surgical management of intra-abdominal inflammatory conditions during pregnancy. Surg Clin North Am 75(1): 15-31.

[4]. Reedy MB, Galan HL, Richards WE, Preece CK, Wetter PA, et al. (1997) Laparoscopy during pregnancy. A survey of laparoendoscopic surgeons. J Reprod Med 42(1): 33-38.

[5]. Fatum M, Rojansky N (2001) Laparoscopic surgery during pregnancy. Obstet Gynecol Surv 56(1): 50-59.

[6]. Curet MJ, Allen D, Josloff RK, Pitcher DE, Curet LB, et al. (1996) Laparoscopy during pregnancy. Arch Surg 131(5): 546-550.

[7]. Rizzo AG (2003) Laparoscopic surgery in pregnancy: long-term follow-up. J Laparoendosc Adv Surg Tech 13(1): 11-15.

[8]. Andreoli M, Servakov M, Meyers P, Mann WJ Jr (1999) Laparoscopic surgery during pregnancy. J Am Assoc Gynecol Laparosc 6(2): 229-233.

[9]. Shay DC, Bhavani-Shankar K, Datta S (2001) Laparoscopic surgery during pregnancy. Anesthesiol Clin North America 19(1): 57-67.

[10]. Oelsner G, Stockheim D, Soriano D, Goldenberg M, Seidman DS, et al. (2003) Pregnancy outcome after laparoscopy or laparotomy in pregnancy. J Am Assoc Gynecol Laparosc 10(2): 200-204.

[11]. McKellar DP, Anderson CT, Boynton CJ, Peoples JB (1992) Cholecystectomy during pregnancy without fetal loss. Surg Gynecol Obstet 174(6): 465-468.

[12]. Glasgow RE, Visser BC, Harris HW, Patti MG, Kilpatrick SJ, et al. (1998) Changing management of gallstone disease during pregnancy. Surg Endosc 12(3): 241-246.

[13]. Affleck DG, Handrahan DL, Egger MJ, Price RR (1999) The laparoscopic management of appendicitis and cholelithiasis during pregnancy. Am J Surg 178(6): 523-529.

[14]. Barone JE, Bears S, Chen S, Tsai J, Russell JC (1999) Outcome study of cholecystectomy during pregnancy. Am J Surg 177(3): 232-236.

[15]. Rollins MD, Chan KJ, Price RR (2004) Laparoscopy for appendicitis and cholelithiasis during pregnancy: a new standard of care. Surg Endosc 18(2): 237-241.

[16]. Davis A, Katz VL, Cox R (1995) Gallbladder disease in pregnancy. J Reprod Med 40(11): 759-762.

[17]. Geisler JP, Rose SL, Mernitz CS, Warner JL, Hiett AK (1998) Non-gynecologic laparoscopy in second and third trimester pregnancy: obstetric implications. JSLS 2(3): 235-238.

[18]. Stepp K, Falcone T (2004) Laparoscopy in the second trimester of pregnancy. Obstet Gynecol Clin North Am 31(3): 485-496.

[19]. Pucci RO, Seed RW (1991) Case report of laparoscopic cholecystectomy in the third trimester of pregnancy. Am J Obstet Gynecol 165(2): 401-402.

[20]. Weber AM, Bloom GP, Allan TR, Curry SL (1991) Laparoscopic cholecystectomy during pregnancy. Obstet Gynecol 78(5 Pt 2): 958-959.

[21]. Arvidsson D, Gerdin E (1991) Laparoscopic cholecystectomy during pregnancy. Surg Laparosc Endosc 1(3): 193-194.

[22]. Costantino GN, Vincent GJ, Mukalian GG, Kliefoth WL Jr (1994) Laparoscopic cholecystectomy in pregnancy. J Laparoendosc Surg 4(2): 161-164.

[23]. Soriano D, Yefet Y, Seidman DS, Goldenberg M, Mashiach S, et al. (1999) Laparoscopy versus laparotomy in the management of adnexal masses during pregnancy. Fertil Steril 71(5): 955-960.

[24]. Curet MJ (2000) Special problems in laparoscopic surgery. Previous abdominal surgery, obesity, and pregnancy. Surg Clin North Am 80(4): 10931110 .

[25]. Walton NKD, Melachuri VK (2006) Anaesthesia for non-obstetric surgery during pregnancy. Continuing Education in Anaesthesia, Critical Care \& Pain 6(2): 83-85.

[26]. Elkayam U, Gleicher N (1982) Cardiovascular physiology of pregnancy. Alan R Liss, New York. 5-26.

[27]. Clark SL, Cotton DB, Pivarnik JM, Lee W, Hankins GD, et al. (1991)
Position change and central hemodynamic profile during normal third-trimester pregnancy and post partum. Am J Obstet Gynecol 164(3): 883-887.

[28]. Akira S, Yamanaka A, Ishihara T, Takeshita T, Araki T (1999) Gasless laparoscopic ovarian cystectomy during pregnancy: comparison with laparotomy. Am J Obstet Gynecol 180(3 Pt 1): 554-557.

[29]. Murakami T, Noda T, Okamura C, Terada Y, Morito Y, et al. (2003) Cul-desac packing with a metreurynter in gasless laparoscopic cystectomy during pregnancy. J Am Assoc Gynecol Laparosc 10(3): 421-423.

[30]. Iafrati MD, Yarnell R, Schwaitzberg SD (1995) Gasless laparoscopic cholecystectomy in pregnancy. J Laparoendosc Surg 5(2): 127-130.

[31]. Hume RF, Killiam AP (1990) Maternal Physiology. In Obstetrics and Gynecology. JB Lippincott, Philadelphia. 93-100.

[32]. Society of American Gastrointestinal Endoscopic Surgeons (SAGES). (1998) Guidelines for laparoscopic surgery during pregnancy. Surg Endosc 12(2): 189-190.

[33]. Hunter JG, Swanstrom L, Thornburg K (1995) Carbon dioxide pneumoperitoneum induces fetal acidosis in a pregnant ewe model. Surg Endosc 9(3): 272-277.

[34]. Curet MJ, Vogt DA, Schob O, Qualls C, Izquierdo LA, Zucker KA (1996) Effects of $\mathrm{CO} 2$ pneumoperitoneum in pregnant ewes. J Surg Res 63(1): 339-344.

[35]. Barnard JM, Chaffin D, Droste S, Tierney A, Phernetton T (1995) Fetal response to carbon dioxide pneumoperitoneum in the pregnant ewe. Obstet Gynecol 85(5 Pt 1): 669-674.

[36]. Cruz AM, Southerland LC, Duke T, Townsend HG, Ferguson JG, et al. (1996) Intraabdominal carbon dioxide insufflation in the pregnant ewe. Uterine blood flow, intraamniotic pressure, and cardiopulmonary effects. Anesthesiology 85(6): 1395-1402.

[37]. Soper NJ, Hunter JG, Petrie RH (1992) Laparoscopic cholecystectomy during pregnancy. Surg Endosc 6(3): 115-117.

[38]. Comitalo JB, Lynch D (1994) Laparoscopic cholecystectomy in the pregnant patient. Surg Laparosc Endosc 4(4): 268-271.

[39]. Bhavani-Shankar K, Steinbrook RA, Brooks DC, Datta S (2000) Arterial to end-tidal carbon dioxide pressure difference during laparoscopic surgery in pregnancy. Anesthesiology 93(2): 370-373.

[40]. Melnick DM, Wahl WL, Dalton VK (2004) Management of general surgical problems in the pregnant patient. Am J Surg 187(2): 170-180.

[41]. Jorgensen JO, Lalak NJ, North L, Hanel K, Hunt DR, et al. (1994) Venous stasis during laparoscopic cholecystectomy. Surg Laparosc Endosc 4(2): 128-133.

[42]. Lowe GDO, Greer IA, Cooke TG, Dewar EP, Evans MJ, et al. (1992) Risk of and prophylaxis for venous thromboembolism in hospital patients. BM] 305(6853): 567-574.

[43]. Casele HL (2006) The use of unfractionated heparin and low molecular weight heparins in pregnancy. Clin Obstet Gynecol 49(4): 895-905.

[44]. Sharp HT (2002) The acute abdomen during pregnancy. Clin Obstet Gynecol 45(2): 405-413.

[45]. Katz VL, Farmer RM (1999) Controversies in tocolytic therapy. Clin Obstet Gynecol 42(4): 802-819.

[46]. Higuchi H, Adachi Y, Arimura S, Kanno M, Satoh T (2001) Early pregnancy does not reduce the $\mathrm{C}(50)$ of propofol for loss of consciousness. Anesth Analg 93(6): 1565-1569.

[47]. Gin T, Mainland P, Chan MT, Short TG (1997) Decreased thiopental requirements in early pregnancy. Anesthesiology 86(1): 73-78.

[48]. Baraka A, Jabbour S, Tabboush Z, Sibai A, Bijjani A, et al. (1992) Onset of vecuronium neuromuscular block is more rapid in patients undergoing caesarean section. Can J Anaesth 39(2): 135-138.

[49]. Dailey PA, Fisher DM, Shnider SM, Baysinger CL, Shinohara Y, et al. (1984) Pharmacokinetics, placental transfer, and neonatal effects of vecuronium and pancuronium administered during cesarean section. Anesthesiology 60(6): 569-574.

[50]. Shnider SM (1965) Serum cholinesterase activity during pregnancy, labor and puerperium. Anesthesiology 26: 335-339.

[51]. Whittaker M, Crawford JS, Lewis M (1988) Some observations of levels of plasma cholinesterase activity within an obstetric population. Anaesthesia 43(1): 42-45.

[52]. Gin T, Chan MT (1994) Decreased minimum alveolar concentration of isoflurane in pregnant humans. Anesthesiology 81(4): 829-832.

[53]. Chan MT, Mainland P, Gin T (1996) Minimum alveolar concentration of halothane and enflurane are decreased in early pregnancy. Anesthesiology 85(4): 782-786

[54]. Yildiz K, Dogru K, Dalgic H, Serin IS, Sezer Z, et al. (2005) Inhibitory effects of desflurane and sevoflurane on oxytocin-induced contractions of isolated pregnant human myometrium. Acta Anaesthesiol Scand 49(9): 1355-1359.

[55]. Volmanen P, Akural E, Raudaskoski T, Ohtonen P, Alahuhta S (2005) Comparison of remifentanil and nitrous oxide in labour analgesia. Acta Anaesthesiol Scand 49(4): 453-458 